\title{
Size-dependent in vivo/in vitro results of homoeopathic herbal extracts
}

\author{
Rajesh Barve ${ }^{1}$ and Ramesh Chaughule $2^{*^{*}}$
}

\begin{abstract}
This paper presents evidence-based results of clinical trial on the use of nanosized particles in homoeopathic Terminalia arjuna tincture. Dynamic light scattering technique demonstrates that homoeopathic tincture is a mixture of particles varying from micron to nanometre sizes. The process of succussion, homogenization and filtration brings down the particles of source material to nanosize as a 'top-down' process. As compared to the conventionally used micron-sized T. arjuna powder, the results show significant clinical improvement due to the presence of nanoparticles in tincture by the above method. Similar results were reconfirmed on experiments with bacterial cultures. From clinical trials, it has been confirmed that the dose of medicine required by the patient is significantly reduced with the reduction in particle size. No toxicity was observed even after giving medicine for more than 8 weeks. Size-dependent sensitivity of the drug can help to tackle the problem of drug resistance in bacteria.
\end{abstract}

Keywords: Lipid profile, Terminalia arjuna, Homoeopathy, Clinical trials, DLS method, Holarrhena antidysenterica, E. coli cultures, Zone of inhibition

\section{Background}

Holarrhena antidysenterica is a tropical plant which grows up to $5 \mathrm{~m}$ in height. The bark extract of this plant is used in ayurvedic and homoeopathic systems of medicine for the treatment of tropical diarrhoeas and dysentery. It belongs to Apocynaceae family. Around 30 alkaloids have been isolated from the plant, mostly from the bark. These include conessine, kurchine, kurchicine, holarrhimine, conarrhimine, conaine, conessimine, isoconessimine, conimine, holacetin and conkurchin [1]. It is a well-known drug for amoebic dysentery and other gastric disorders. It is also indicated for the treatment of diarrhoea, indigestion, flatulence and colic [2]. Homoeopathic system of medicine uses ethanolic extracts, called as mother tincture, and their dilutions (potencies). As per the Homoeopathic Pharmacopoeia of India standard, the drug strength is $1 / 10$. Since there is no standardization criterion for the particle size of the tincture, the experimentation was carried out by changing the particle size of the tincture, and size-related effects were compared in vitro.

\footnotetext{
*Correspondence: rsctifr@yahoo.com

${ }^{2}$ Department of Chemistry, Ramnarain Ruia College, Matunga, Mumbai 400019, India

Full list of author information is available at the end of the article
}

Terminalia arjuna is known over 2,000 years as good cardioprotective medicine. Many useful phytoconstituents have been isolated from $T$. arjuna which includes triterpenoids for cardiovascular properties, tannins and flavonoids for its anticancer properties and so on. The bark leaves and fruits of T. arjuna have been used in the indigenous system of medicine for different ailments [3]. The bark contains a very high level of flavonoids compared to other commonly used plant items. Flavonoids detected from its bark are arjunolone, flavones, bicalein, quercetin, kempferol and pelorgonidin [4-6]. Traditionally in ayurvedic medicine, $T$. arjuna powder with a dose of 1 to $2 \mathrm{~g} /$ day and an average powder size of about $50 \mu \mathrm{m}$ is used for the patients. T. arjuna is also known to reduce lipid levels. This was verified by in vivo studies on 32 hyperlipidemic patients by giving them this mother tincture which has much lesser particle size.

\section{Results and discussions}

Table 1 shows the results of ten patients who took $T$. arjuna dose of $0.083 \mathrm{~g}$ for 8 weeks or more. The patients showed significant reduction in low-density lipoprotein (LDL), very low-density lipoprotein (VLDL), triglyceride (TG) and total cholesterol as compared to the traditional dose of 1 to $2 \mathrm{~g} /$ day of $T$. arjuna powder 
Table 1 In vivo experiment of $T$. arjuna tincture for certain

\begin{tabular}{|c|c|c|c|c|c|}
\hline $\begin{array}{l}\text { Patient } \\
\text { number }\end{array}$ & $\begin{array}{c}\text { Total } \\
\text { cholesterol } \\
\text { reduction (\%) }\end{array}$ & $\begin{array}{c}\mathrm{HDL} \\
\text { increase } \\
(\%)\end{array}$ & $\begin{array}{l}\mathrm{LDL} \\
\text { reduction } \\
(\%)\end{array}$ & $\begin{array}{l}\text { VLDL } \\
\text { reduction } \\
\text { (\%) }\end{array}$ & $\begin{array}{c}\text { TG } \\
\text { reduction } \\
(\%)\end{array}$ \\
\hline 1 & 27 & 36 & 35 & 45 & 46 \\
\hline 5 & 25.8 & & 41.8 & 19 & 18.9 \\
\hline 8 & 37 & 50 & 30 & - & 23.2 \\
\hline 11 & 42 & 21 & 37 & - & 5.2 \\
\hline 13 & 23 & 5 & 26.1 & 24.2 & 23.9 \\
\hline 20 & 28 & 7.1 & 39 & 10 & 31.5 \\
\hline 25 & 15.6 & 14.2 & 25.2 & 50 & 46.9 \\
\hline 27 & 13.8 & 33.3 & 24.8 & 41.6 & 41.6 \\
\hline 29 & 25.4 & 21 & 46.2 & 33.3 & 12.2 \\
\hline 30 & 17.7 & 4.6 & 11.1 & 42.3 & 48.7 \\
\hline
\end{tabular}

with a mean particle size of $50 \mu \mathrm{m}$ available in the market. There is also an increase in high-density lipoprotein (HDL) levels by about $20 \%$ which is hardly seen in any other anti-lipid drug as HDL is cardioprotective. Figure 1 represents Escherichia coli M200 culture with 2.67- $\mu \mathrm{m}$ particle size of Holarrhena tincture on LHS plate showing no zone of inhibition. However, with 13.8-nm particle size of the same tincture on RHS plate, E. coli M200 gives $10 \mathrm{~mm}$ of zone inhibition. Figure 2 represents E. coli 10536 culture with Holarrhena tincture of particle size $2.67 \mu \mathrm{m}$, and Figure 3 shows E. coli 10536 culture with Holarrhena tincture having particle size of $13.8 \mathrm{~nm}$.

\section{Conclusions}

This study clearly demonstrates particle size-dependent variation in the drug action. Reduction in the particle size of the drug improves the sensitivity of the drug as seen in in vivo experiment of T. arjuna drug. Reduction of particle size from $50 \mu \mathrm{m}$ to $23 \mathrm{~nm}$ showed drastic reduction in dose requirement, i.e. from 1 to $2 \mathrm{~g} /$ day to $0.083 \mathrm{~g} /$ day. No toxicity was observed with this nanodose even after giving for 2 months or more.

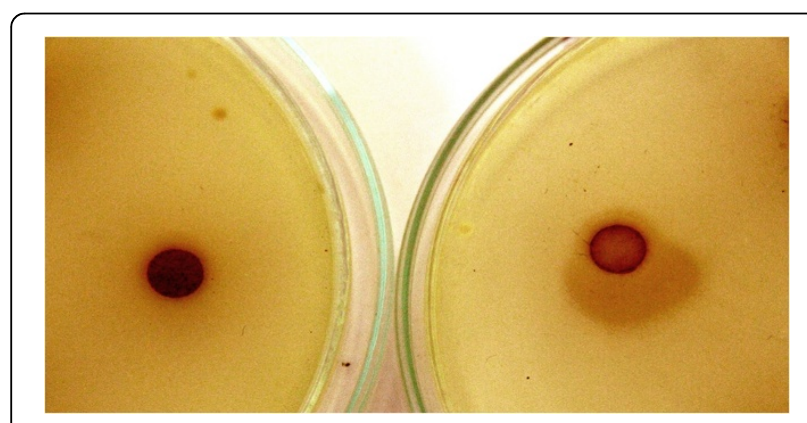

Figure 1 E. coli M200 culture with Holarrhena tincture of 2.67 $\mu \mathrm{m}$ and $13.8 \mathrm{~nm}$ in size.

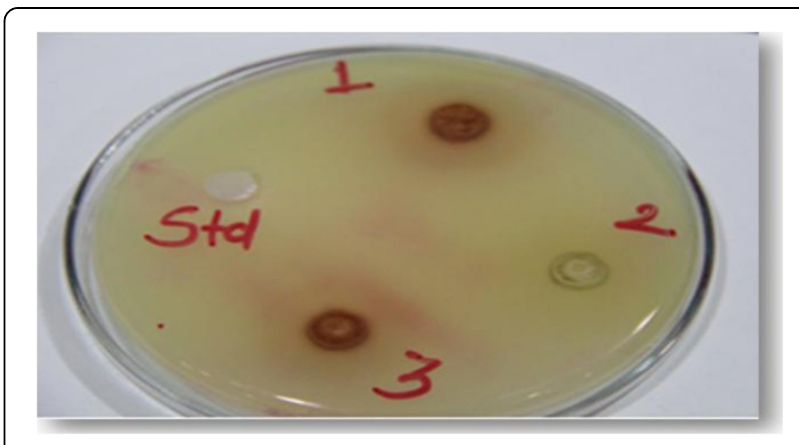

Figure 2 E. coli 10536 culture with Holarrhena tincture of 2.67$\mu \mathrm{m}$ size (1 and 3), alcohol (2) and blank disc (Std).

From in vitro experiments with $E$. coli, it is clear that reduction of particle size of tincture improved the culture results by $15 \%$ or more. Interestingly, E. coli M200 showed resistance to Holarrhena tincture at 2.67- $\mu \mathrm{m}$ particle size but showed sensitivity at 13.8 -nm particle size tincture. This phenomenon is reported for the first time and can help to reduce drug resistance problem for the patients in the future.

\section{Methods}

T. arjuna tincture manufactured by Bakson, India was used for in vivo clinical trials using the dynamic light scattering (DLS) system of Aimil Malvern Instruments from Baroda. Its mean particle size was $23 \mathrm{~nm}$ (Figure 4). Holarrhena tincture also manufactured by Bakson, India was used for bacterial studies. The particle size determined by DLS was found to be 2.67 $\mu \mathrm{m}$ (Figure 5). Further reduction in particle size of this tincture to $13.8 \mathrm{~nm}$ (Figure 6) was achieved by standard succussion, homogenization and filtration methods.

Four pathogenic strains of E. coli (11100, 11105, 10536, M200) were collected and inoculated in culture plates (Table 2). Nutrient agar was used as culture media. Sterile Whatman paper discs of 5mm-diameter size were impregnated with $0.1 \mathrm{ml}$ Holarrhena antidysenterica tincture with particle sizes of $2.67 \mu \mathrm{m}$ and $13.8 \mathrm{~nm}$, respectively. Discs

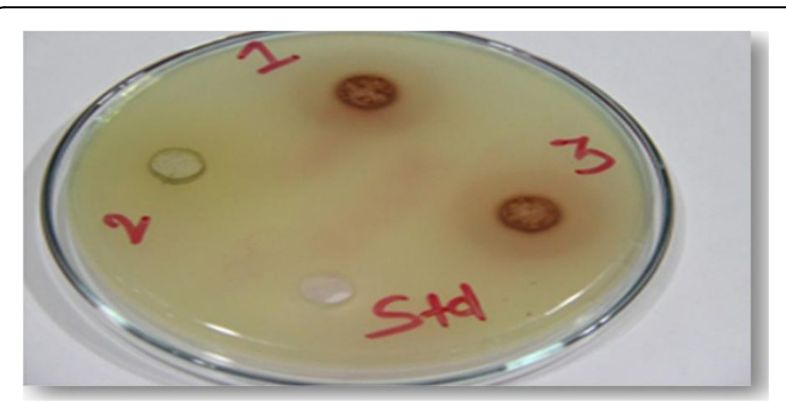

Figure 3 E. coli 10536 culture with Holarrhena tincture of 13.8nm size (1 and 3), alcohol (2) and blank disc (Std). 

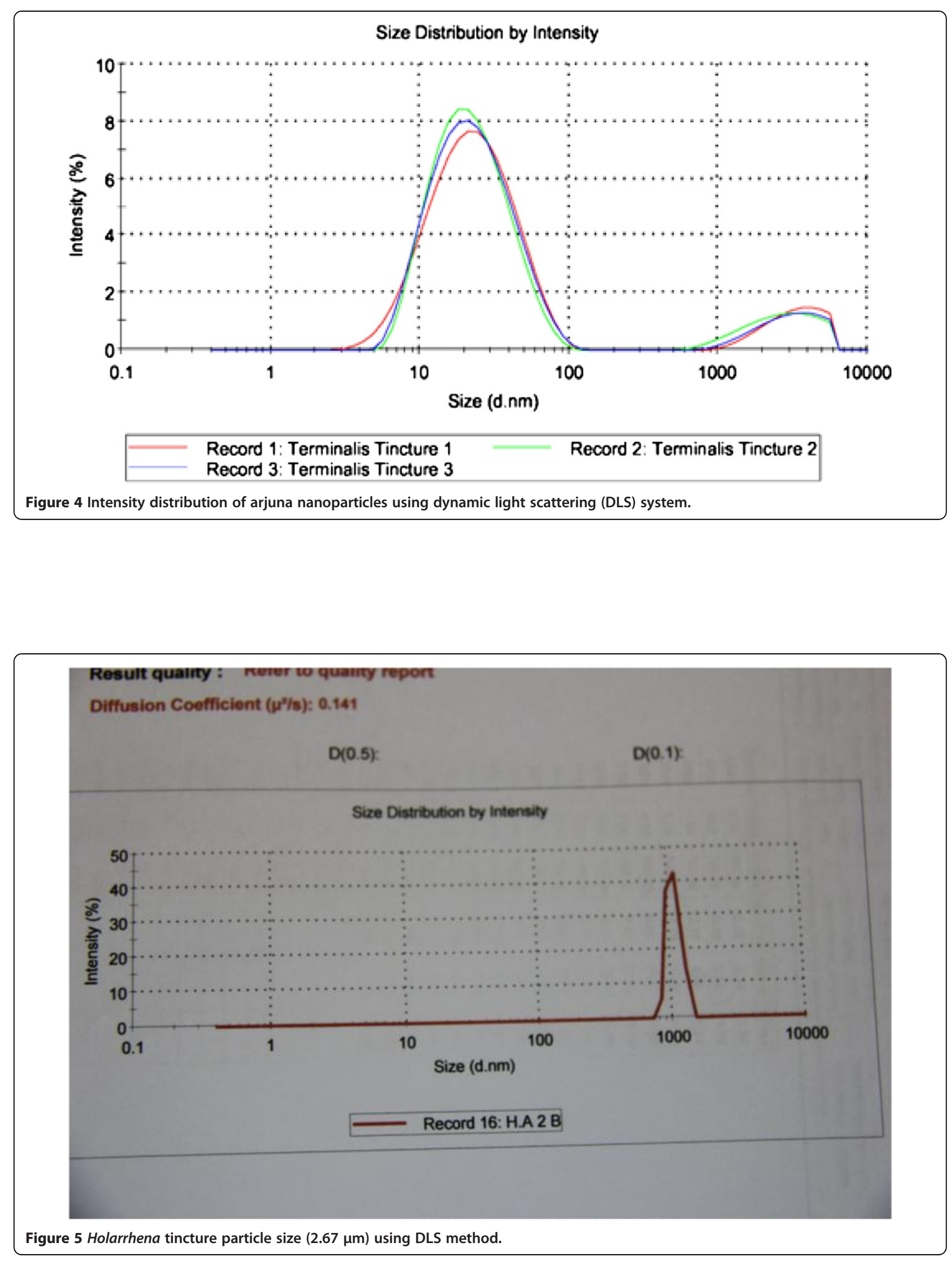


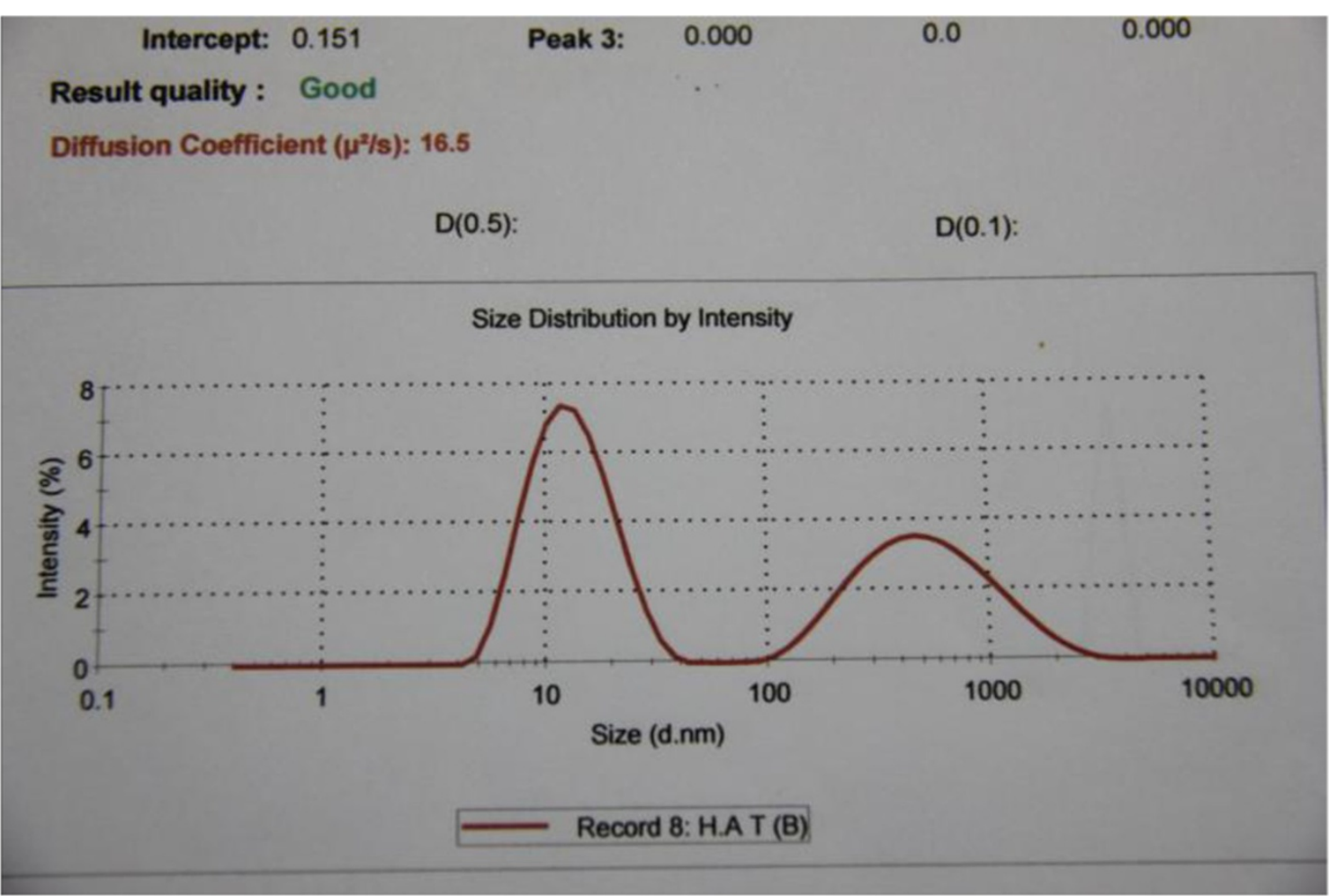

Figure 6 Reduction of Holarrhena tincture particle size $(13.8 \mathrm{~nm})$.

were placed on agar media inoculated with bacterial cultures. The disc with $0.1 \mathrm{ml}$ ethanol was kept as a control since tinctures contain $60 \%$ ethanol. Culture plates were incubated at $32^{\circ} \mathrm{C}$ for $36 \mathrm{~h}$ to get good bacterial colonies. Finally, zones of inhibitions were measured and compared to know the efficacy of the drug and effect of particle sizes (Figures 1, 2, 3).

All 32 hyperlipidemic patients, who were not taking any anti-lipid medicines, were randomly selected. Their vital data regarding lipid levels, diet, habits, type of work, stress level and history of present- and pastassociated illnesses were noted. Every patient was given oral dose of 10 drops of $T$. arjuna tincture with water at bedtime. The calculated weight of this $23-\mathrm{nm}$ particle size tincture dose is $0.083 \mathrm{~g}$. Dose was given for 8 weeks and more to compare the changes in lipid levels (Table 1).

Table 2 E. coli and $H$. antidysenterica tincture

\begin{tabular}{lcc}
\hline & \multicolumn{1}{c}{ Holarrhena tincture zone of inhibition $(\mathbf{m m})$} \\
\cline { 2 - 3 } & $\mathbf{2 . 6 7} \boldsymbol{\mu m}$ & $\mathbf{1 3 . 8} \mathbf{~} \mathbf{m}$ \\
\hline E. coli M200 & No zone & 10 \\
E. coli 10536 & 24 & 26 \\
E. coli 11105 & 22 & 25 \\
E. coli 11100 & 24 & 25 \\
\hline
\end{tabular}

Competing interests

The authors declare that they have no competing interests.

\section{Authors' contributions}

$\mathrm{RB}$ and RC carried out the T. arjuna and Hollarrhena antidysenterica studies and participated in the experimental work on the in vitro studies of bacterial cultures. RB treated the specific patients in his clinic by giving nanodose of T. arjuna tincture. Both the authors provided the same contributions in this article and read and approved the final manuscript.

\section{Acknowledgements}

The authors gratefully thank Dr. Medha Shette, Dr. Vivek Athavale and Dr. Pusalkar for their help in the pathological work.

\section{Author details}

'Department of Repertory, Virar Homoeopathic Medical College, Virar, 401305, Maharashtra, India. ${ }^{2}$ Department of Chemistry, Ramnarain Ruia College, Matunga, Mumbai 400019, India.

Received: 13 March 2013 Accepted: 4 April 2013 Published: 23 April 2013

\section{References}

1. Kumar, N, Singh, B, Bhandari, P, Gupta, AP, Kaul, VK: Steroidal alkaloids from Holarrhena antidysenterica (L.) Wall. Chem. Pharm. Bull (Tokyo) 55(6), 912 (2007)

2. Singh, KP: Clinical studies of amoebiasis and giardiasis evaluating the efficacy of kutaja (Holarrhena autidysenterica) in Eutamoeta histotylica cyst passes. Ancient Science of Life 5, 228-231 (1986)

3. Warrier, PK, Nambiar, VPK, Ramankutty, C: Indian Medicinal Plants: A Compendium of 500 Species, p. 592. Orient Blackswan, India (1996)

4. Sharma, PN, Shoeb, PN, Kapil, RS, Popli, SP: Arjunolone - a new flavone from stem bark of Terminalia arjuna. Indian Journal of Chemistry 21B, 263 (1982) 
5. Nema, R, Jain, P, Khare, S, Pradhan, A, Gupta, A, Singh, D: Preliminary phytochemical evaluation and flavonoids quantification of Terminalia arjuna leaves extract. Int. J. Pharm. Phytopharmacol. Res. 1(5), 283 (2012)

6. Nema, R, Jain, P, Khare, S, Pradhan, A, Gupta, A, Singh, D: Antibacterial and antifungal activity of Terminalia arjuna leaves extract with special reference to flavonoids. Basic Research J. Med. Clin. Sc. 1(5), 63 (2012)

doi:10.1186/2193-8865-3-18

Cite this article as: Barve and Chaughule: Size-dependent in vivo/in vitro results of homoeopathic herbal extracts. Journal Of Nanostructure in Chemistry 2013 3:18.

\section{Submit your manuscript to a SpringerOpen ${ }^{\circ}$} journal and benefit from:

- Convenient online submission

- Rigorous peer review

- Immediate publication on acceptance

- Open access: articles freely available online

- High visibility within the field

- Retaining the copyright to your article

Submit your next manuscript at $\gg$ springeropen.com 